Article

\title{
Comparative Analysis of Mechanical Properties and Metal-Ceramic Bond Strength of Co-Cr Dental Alloy Fabricated by Different Manufacturing Processes
}

\author{
Xingting Han ${ }^{1,+}{ }^{+}$Tomofumi Sawada ${ }^{1,2,+}{ }^{\mathbb{C}}$, Christine Schille $^{1}$, Ernst Schweizer ${ }^{1}$, \\ Lutz Scheideler ${ }^{1}{ }^{\circledR}$, Jürgen Geis-Gerstorfer ${ }^{1}$, Frank Rupp ${ }^{1}$ and Sebastian Spintzyk ${ }^{1, *}$ \\ 1 Section Medical Materials Science and Technology, University Hospital Tübingen, Osianderstr. 2-8, \\ Tübingen 72076, Germany; xingting.han@student.uni-tuebingen.de (X.H.); \\ Tomofumi.Sawada@med.uni-tuebingen.de (T.S.); Christine.Schille@med.uni-tuebingen.de (C.S.); \\ ernst.schweizer@med.uni-tuebingen.de (E.S.); lutz.scheideler@med.uni-tuebingen.de (L.S.); \\ juergen.geis-gerstorfer@med.uni-tuebingen.de (J.G.-G.); Frank.Rupp@med.uni-tuebingen.de (F.R.) \\ 2 Department of Biomedical Engineering, Iwate Medical University, 2-1-1 Nishitokuta, Yahaba-cho, \\ Shiwa-gun, Iwate 028-3694, Japan \\ * Correspondence: Sebastian.Spintzyk@med.uni-tuebingen.de; Tel: +49-707-1298-3995 \\ + These authors contributed equally to this work.
}

Received: 13 July 2018; Accepted: 20 September 2018; Published: 22 September 2018

\begin{abstract}
Cobalt-chromium (Co-Cr) alloy is a widely used base material for dental fixed prostheses. These restorations can be produced through casting technique, subtractive or additive manufacturing technologies. However, limited information is available regarding the influence of manufacturing techniques on the properties of $\mathrm{Co}-\mathrm{Cr}$ alloy since most studies used different chemical compositions of $\mathrm{Co}-\mathrm{Cr}$ alloy for different manufacturing methods. This study compares the mechanical properties, metal-ceramic bond strength, and microstructures of specimens produced by casting, milling, and selective laser melting (SLM) from one single $\mathrm{Co}-\mathrm{Cr}$ alloy composition. The mechanical properties of the alloy were investigated by tensile and Vickers hardness tests, and metal-ceramic bond strength was determined by three-point bending. Scanning electron microscopy (SEM) with backscattered electron (BSE) images and optical microphotographs were used to analyze the surface microstructures. Compared with the casting and milling techniques, SLM Co-Cr alloy specimens indicated enhanced mechanical properties and comparable metal-ceramic bond strength. Besides, the microstructures of the SLM specimens showed finer grains with more second phase particles than the casting and milling specimens. The results of our study indicate that SLM might be superior to traditional techniques for the manufacturing of fixed dental restorations.
\end{abstract}

Keywords: Cobalt-chromium (Co-Cr) alloy; additive manufacturing; selective laser melting (SLM); milling; casting; mechanical properties; bond strength; microstructure; dental prostheses

\section{Introduction}

Metal-ceramic prostheses, which are known as the porcelain-fused-to-metal (PFM) restorations, have been widely used in fixed dental prosthodontics because of the proper mechanical and aesthetic properties [1,2]. Among many different noble and base dental alloys, cobalt-chromium $(\mathrm{Co}-\mathrm{Cr})$ is one of the common alloys to fabricate the substrate of metal-ceramic restorations because of the low cost, high mechanical strength, and good corrosion resistance [3,4].

Traditionally, Co-Cr substrates are fabricated by the lost-wax casting technique, which is still the dominant method in dental metal processing. However, this technique requires a lot of time and certain skills for dental technicians and often results in pores and defects in the interior of the alloy $[5,6]$. 
Recently, computer-aided design and computer-aided manufacturing (CAD-CAM) technology has been introduced to fabricate the substrates. This technology can be divided into two main categories: Subtractive manufacturing processes like milling, and additive manufacturing processes like selective laser melting (SLM). Milling usually uses tools, such as saws, lathes, grinders, and drill presses to mechanically cut the block to the desired geometry, are controlled by a computer program. Milling can reduce flaws and pores which may be caused by the casting process because the $\mathrm{Co}-\mathrm{Cr}$ blanks are made under high industrial standards, and the sample precision is related to the cutting performance [7]. The disadvantages of milling are the waste of materials and limited potential for complex products compared with casting and SLM [8]. SLM is a laser-based additive manufacturing technology, which is widely used in medical fields in recent years, especially for dental restorations like customized crowns, bridges, abutments, and screw-retained restorations [9-13]. SLM produces the metal substrate by fusing metal powder in layers without much porosity. This technique uses a focused high-power laser beam and results in products of nearly $100 \%$ density. The laser could also be the key to harden metals and ceramics [14]. Furthermore, objects with complex geometries are achievable with a high-dimensional accuracy [15-18]. Compared to casting and milling processes, SLM reduces the probability of operator errors, minimizes defects and wastes almost no material since the remaining powder can be used further [19].

For the longevity of clinical use, PFM restorations have to comply with certain requirements, including mechanical properties, metal-ceramic bond strength, biocompatibility, and corrosion resistance [20]. While SLM is a promising technique for the fabrication of prostheses, the lack of investigations of mechanical properties and metal-ceramic bond strength of SLM-processed restorations is still a significant drawback [21]. These properties must be further investigated to ensure that the quality of SLM prostheses is at least equal to those produced by conventional techniques [22]. Under a variety of testing methods, the tensile test and three-point bending test (Schwickerath crack initiation test), which were promulgated in ISO 9693-1: 2012 and ISO 22674: 2016 for dental restorations, are the most common standards to evaluate the mechanical properties and metal-ceramic bond strength in dental research $[23,24]$. The mechanical properties of the alloy can be influenced by porosity, grain size, and second-phase particles $[25,26]$. Metal-ceramic bond strength is related to Young's (elastic) modulus, chemical bonding, mechanical interlocking, compressive bonding, and van der Waals forces, among those, chemical bonding dominates [6,27-29]. The chemical bonding can be changed when an oxide layer forms on the surface. The oxides are formed while wetting the alloy with veneering ceramic. A thin oxide layer can be eliminated during ceramic firing and gain an excellent bond strength. Whereas, an excessively thick oxide layer may allow more oxide from the ceramic to participate in the chemical reaction and lead to a broader interaction region, and thus weaken the chemical bonding [30-32]. Besides, it is essential to characterize microstructures due to their possible relationship with mechanical properties and the metal-ceramic bond strength, using methods like scanning electron microscopy (SEM) with backscattered electron (BSE) images, and optical microscopy [33]. Normally, SLM has a finer grain size compared to conventional casting technique due to the rapid cooling rate during the building process, which permits the production of bulk objects with very fine microstructures and enhanced mechanical properties [34].

Some studies have already compared the characteristics of Co-Cr alloys fabricated by casting, milling and SLM $[6,26,35,36]$. However, in their reports, different chemical compositions of the alloys for different manufacturing processes were used, which may be due to the limitations of techniques and materials [6,36-39]. Recently, only one publication has examined the shear bond strength of a Co-Cr alloy with the same chemical composition manufactured by different processes [5]. In the study of Antanasova et al., no significant difference in shear bond strength of Co-Cr alloy by casting, milling, and SLM was found. This result is probably because, after the firing process, the samples by different manufacturing methods had similar oxidation properties, resulting in similar chemical bonds. Besides, the similar Young's modulus among different groups also plays an essential role in the bond strength due to the same rigidity to resist bending and delamination [5]. To estimate the reliability of the 
real effect of manufacturing techniques on alloy properties and eliminate the influence of chemical composition, we prepared the specimens using a $\mathrm{Co}-\mathrm{Cr}$ alloy with entirely the same composition throughout casting, milling and SLM groups. The null hypothesis is that different manufacturing processes will not influence the mechanical properties of $\mathrm{Co}-\mathrm{Cr}$ alloy and metal-ceramic bond strength.

\section{Materials and Methods}

The flow chart of the experiment is presented in Figure 1. Co-Cr alloy specimens and substrates for mechanical properties test and metal-ceramic bond strength test were fabricated by three manufacturing methods. The groups and materials used in this study are presented in Table 1.

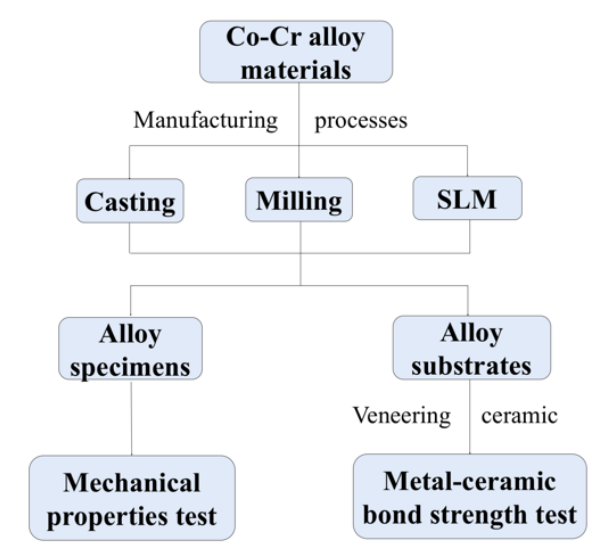

Figure 1. The flow chart of the experiment.

Table 1. Specification of the alloy and ceramic used in this study.

\begin{tabular}{cccccc}
\hline Materials & Brand Name & Material Type & Composition (wt \%) & CTE $\left(\times \mathbf{1 0}^{-\mathbf{6}} \mathbf{K}^{-\mathbf{1}}\right)$ & Manufacturer $^{\text {\% }}$ \\
\hline \multirow{2}{*}{ Co-Cr Alloy } & Remanium Star & Metal ingots: casting & Co 60.5\%, Cr 28\%, W 9\%, Si & 14.1 & Dentaurum, \\
& Remanium Star MDI & Metal blank: milling & 1.5\%, Other & 14.1 & Ispringen, \\
& Remanium Star CL & Metal powder: SLM & $($ Mn, N, Nb, Fe) < 1\% & 14.1 & Germany \\
\hline Ceramic & Ceramotion Me & Dental ceramic & Glass (silica) based ceramic & $13.9-15.1$ & \\
\hline
\end{tabular}

CTE: coefficient of thermal expansion.

\subsection{Specimen Preparation and Characterization of the Surface}

\subsubsection{Specimens Preparation for Mechanical Properties Test}

For the mechanical properties test, metal specimens were fabricated by casting, milling, and SLM manufacturing processes ( $n=6$ per group). The dumbbell-shaped dimension of the specimens according to ISO 22674: 2016 is presented in Figure 2a [24].
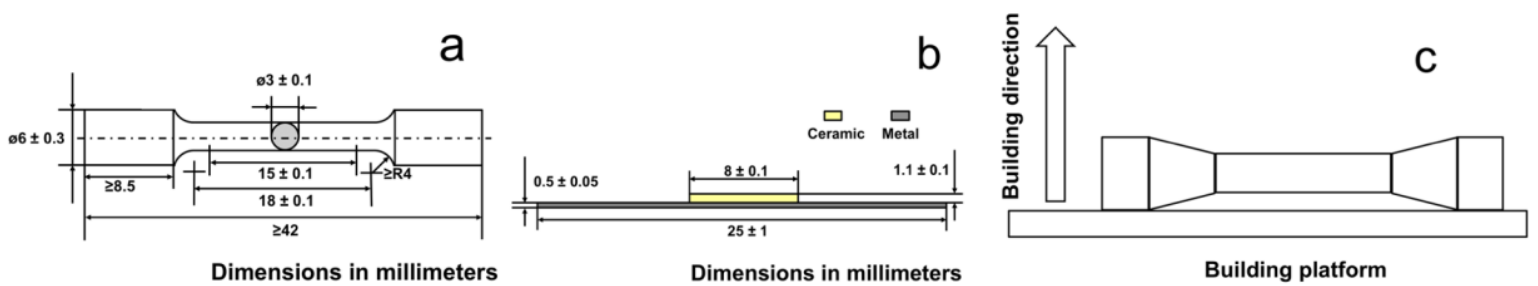

Figure 2. Schematic drawing of the testing specimens with specified dimensions for mechanical properties test (a) and metal-ceramic bond strength test (b), according to ISO 22674: 2016 and ISO 9693-1: 2012. (c) The building direction of the SLM specimens.

In the casting group, $\mathrm{Co}-\mathrm{Cr}$ samples were manufactured by the conventional lost wax technique. Wax rods were cut into a dumbbell-shaped dimension as a template and mounted in a silicone ring. After modeling with the inlay casting wax, samples were invested in phosphate-bonded investment (Onyx, Heraeus-Kulzer, Hanau, Germany). Then, the rings were put into a furnace (Mihm + Voght, 
Stutensee, Germany) to evaporate the wax. The casting was accomplished using the Co-Cr alloy ingots (Remanium Star, Dentaurum, Ispringen, Germany) in a casting device (Combilabor CL-I 95, Heraeus-Kulzer, Hanau, Germany) according to the manufacturer's instructions. For casting samples, there was no post-production heat treatment, after cooling at room temperature, the samples were divested, cleaned, and sandblasted with $125 \mu \mathrm{m} \mathrm{Al}_{2} \mathrm{O}_{3}$ particles under $0.4 \mathrm{MPa}$ pressure (Cemat NT4, Wassermann, Hamburg, Germany).

For the milling group, the samples were designed by CAD software (Exocad Dental Cad, Exocad, Darmstadt, Germany), and then exported to CAM software (Sum3d Dental, CIM system, Cinisello Balsamo, Italy). The specimens were milled from a prefabricated $\mathrm{Co}-\mathrm{Cr}$ alloy blank $(98.4 \mathrm{~mm}$ in diameter and $12 \mathrm{~mm}$ in thickness, Remanium Star MD, Dentaurum, Ispringen, Germany) by a milling machine (550i, imes icore, Eiterfeld, Germany) according to the manufacturer's instructions. Then the milling specimens were cut out using a cutting disc and sandblasted in the same manner as the casting samples. There was no heat treatment after the milling process.

For the SLM group, the samples were also designed by CAD software (Dassault Systemes, Waltham, MA, USA) and transferred to an SLM device (Mlab, Concept Laser, Lichtenfels, Germany) equipped with a $100 \mathrm{~W}$ fiber laser. The size of the Co-Cr powder (Remanium Star CL, Dentaurum, Ispringen, Germany) was 10-40 $\mu \mathrm{m}$. SLM manufacturing parameters were based on the standard process recommended by the manufacturer, the building layer thickness was $25 \mathrm{~mm}$, scan speed was $7 \mathrm{~m} / \mathrm{s}$, manufacturing speed was $5 \mathrm{~cm}^{3} / \mathrm{h}$, Yb-fiber laser power was $100 \mathrm{~W}$, and the longitudinal axes of the specimens was parallel to the building platform (Figure 2c). After fabricating, the SLM samples were subjected to post-build heat treatment in a furnace (Nabertherm N $41 \mathrm{H}$, Lilienthal, Germany) to remove the residual stress arising from the local laser melting and to tailor the microstructure according to the manufacturer's recommendation. The heat treatment was under an argon atmosphere at $1150{ }^{\circ} \mathrm{C}$ for $1 \mathrm{~h}$, then cooling down to furnace temperature $\left(200^{\circ} \mathrm{C}\right)$. After cooling, the samples were removed from the furnace and left to completely cool at room temperature. A dental hand piece (K-POWERgrip, KaVo, Warthausen, Germany) was used for the removal of the supporting structures. After all, the specimens were cleaned and sandblasted in the same manner as the casted samples.

\subsubsection{Specimens Preparation for Metal-Ceramic Bond Strength Test}

The alloy substrates of the metal-ceramic specimens ( $n=109 ; 29$ for the casting group, 40 for the milling group and 40 for the SLM group) were prepared using the same devices and processes. The dimensions of the substrates were $(25 \pm 1) \mathrm{mm} \times(3 \pm 0.1) \mathrm{mm} \times(0.5 \pm 0.05) \mathrm{mm}$ according to ISO 9693-1: 2012 [23]. The opaque ceramic was applied over a length of $(8 \pm 0.1) \mathrm{mm}$ symmetrically on one $3 \mathrm{~mm}$-wide side of each specimen on the substrate surface (Figure $2 \mathrm{~b}$ ). After the manufacturing processes, the surface of the alloy substrates was sandblasted with $125 \mu \mathrm{m} \mathrm{Al}_{2} \mathrm{O}_{3}$ particles, then cleaned with steam and dried with compressed air.

\subsubsection{Surface Characterization}

Before firing the ceramic, four metal substrates were selected randomly from each group to determine the surface roughness. The average roughness $\left(R_{a}\right)$ was measured by profilometry (Perthometer Concept S6P, Mahr, Göttingen, Germany) over the length of $5.6 \mathrm{~mm}$ with 3 single profiles per sample, providing 12 readings totally per group.

\subsubsection{Application of the Veneering Ceramic}

Ceramic powder and liquid (Ceramotion Me, Dentaurum, Germany) were mixed in a vacuum-vibrator and applied in a metal jig. The opaque and dentine firing steps were applied twice on each metal stripe, respectively, followed by the glaze firing step once. The firing processes were performed in a furnace (DEKEMA 3001, Freilassing, Germany) according to the manufacturer's instructions (Table 2). 
Table 2. Firing schedules of the procedure for veneering ceramic.

\begin{tabular}{ccccccc}
\hline Product Name & Pre-Heating Temp. $\left({ }^{\circ} \mathbf{C}\right)$ & Drying Time (min) & Heating Rate $\left({ }^{\circ} \mathbf{C} /\right.$ min) & Final Temp. $\left({ }^{\circ} \mathbf{C}\right)$ & Holding Time $($ min) & Vacuum \\
\hline Paste opaque & 500 & 8 & 75 & 950 & 1 \\
1st Dentin & 500 & 6 & 55 & 870 & + \\
2nd Dentin & 500 & 6 & 55 & 870 & + \\
Glaze & 500 & 6 & 75 & 860 & 1 \\
\hline
\end{tabular}

\subsection{Mechanical Properties Test and Microstructure Analysis}

Mechanical properties were divided into two parts, tensile and Vickers hardness test. The tensile test was performed on the alloy specimen (Figure 2a) according to ISO 22674: 2016 using a universal testing machine Z020 (Zwick, Ulm, Germany) at a crosshead speed of $2 \mathrm{~mm} / \mathrm{min}$ until a fracture occurred [24]. The $0.2 \%$ yield strength $\left(\mathrm{R}_{\mathrm{p} 0.2}\right)$, percentage elongation at fracture, ultimate tensile strength $\left(R_{m}\right)$, and Young's modulus were measured for the tensile test. A Vickers hardness-testing machine (HV 10, Wolpert, Bretzfeld, Germany) was used for hardness testing on the edge area of the dumbbell-shaped specimens, where they were clamped by the specimen grips in the tensile test. A load of $10 \mathrm{~kg}$ was applied for $15 \mathrm{~s}$ of dwelling time.

For the microstructural analysis, three specimens per group were cut along the longitudinal axes to expose the cross-section and embedded in epoxy resin (Orthocryl, Dentaurum, Ispringen, Germany). After polymerization, the cross-section of the specimens was polished with silicon carbide abrasive paper up to P2500, followed by fine polishing using a medium-hard silk gamma cloth with water-based $3 \mu \mathrm{m}$ polycrystalline diamond paste (Metadi II, Buehler, Esslingen, Germany) and suspension (Dialub SW, Buehler, Esslingen, Germany). The polished surfaces were etched with $37 \% \mathrm{HCl}$ with a few drops of $\mathrm{H}_{2} \mathrm{O}_{2}$ until the surface appeared slightly dull. The specimens were rinsed with plenty of water and finally dried with compressed air. The former clamped area by the specimen grips in the tensile test was observed with an SEM/BSE machine (LEO 1430, Zeiss, Oberkochen, Germany, magnification $500 \times, 2000 \times$, and $5000 \times$ ). The grain size could be calculated roughly by software (Measure, Datinf, Tübingen, Germany) with the scaling bar inserted. After defining the length of the scaling bar, the ratio (real length/represented length) was used to measure the widest and narrowest area of the grain. The fractured surface of the specimen was also observed by SEM (LEO 1430, Zeiss, Oberkochen, Germany, magnification $65 \times$ and $1000 \times$ ).

\subsection{Bond Strength Test and Microstructure Analysis}

The metal-ceramic bond strength was measured by the three-point bending test with a universal testing machine Z010 (Zwick, Ulm, Germany). Specimens (Figure 2b) were placed in the bending apparatus ( $20 \mathrm{~mm}$ distance between the supports and $1 \mathrm{~mm}$ radius of the bending piston) with the ceramic positioned opposite to the applied force symmetrically. A crosshead speed of $1.5 \mathrm{~mm} \pm 0.5 \mathrm{~mm} / \mathrm{min}$ was applied until cracking occurred, and the respective failure force $\left(\mathrm{F}_{\text {fail }}\right)$ was recorded for each specimen. The calculation of bond strength $\left(\tau_{b}\right)$ is given by the following equation (ISO 9693: 2012 [23]):

$$
\tau_{\mathrm{b}}=\mathrm{F}_{\text {fail }}\left(\mathrm{A} \times \mathrm{d}_{\mathrm{m}}{ }^{2}+\mathrm{B} \times \mathrm{d}_{\mathrm{m}}+\mathrm{C}\right),
$$

where $\mathrm{A}, \mathrm{B}$, and $\mathrm{C}$ are correction factors, which are calculated by the Young's modulus of the tensile test, and $d_{m}$ is the thickness of the specimens.

After the three-point bending test, first, the crack between metal and ceramic was analyzed by SEM laterally (magnification $1000 \times$ ). Subsequently, the metal-ceramic specimens were debonded manually to analyze the remaining ceramic at the alloy surface. The former contact area of the alloy substrate was characterized with SEM (magnification 1000 $\times$ ) and energy dispersive X-Ray spectroscopy (EDX). An optical microscope (M400, Wild Heerbrugg AG, Heerbrugg, Switzerland, magnification $16 \times$ ) and a software (Measure, Datinf, Tübingen, Germany) were used to analyze the failure mode and area fraction of adhering ceramic after debonding. The failure mode can be classified into three types: Adhesive, less than $20 \%$ of the bonding area is covered by remained ceramic in the 
Co-Cr substrate surface; mixed, ceramic remained more than $20 \%$, but less than $80 \%$, and cohesive was more than $80 \%$ of the alloy surface covered by the remaining ceramic.

\subsection{Statistical Analysis}

SPSS Version 21 (SPSS INC, Chicago, IL, USA) was used for analyzing the data. Shapiro-Wilk and Levene tests were applied to assess the assumptions of data normality and the homogeneity of variances. One-way analysis of variance (ANOVA) was used for data of roughness, elongation, Young's modulus, and area fraction of adhered ceramic, followed by a Tukey post-hoc test $(\alpha=0.05)$. The $\mathrm{R}_{\mathrm{p} 0.2}, \mathrm{R}_{\mathrm{m}}$, Vickers hardness, and bond strength were analyzed by Kruskal-Wallis analysis $(\alpha=0.05)$ for the disobedience of the data normality or homogeneity of variances.

\section{Results}

\subsection{Surface Characteristics of the Metal Substrate}

The $R_{a}$ values for each group are presented in Table 3. The SLM group showed the highest $R_{a}$ value of all the three groups $(p<0.05)$, while there was no statistical difference between the casting and milling groups.

Table 3. Surface roughness (means \pm standard deviations) of the test groups.

\begin{tabular}{cc}
\hline Group & $\mathbf{R}_{\mathbf{a}}(\boldsymbol{\mu m})$ \\
\hline Casting & $1.27 \pm 0.10^{\mathrm{a}}$ \\
Milling & $1.33 \pm 0.10^{\mathrm{a}}$ \\
SLM & $1.51 \pm 0.58^{\mathrm{b}}$ \\
\hline
\end{tabular}

Different lowercase letters in the same column indicate significantly different groups $(p<0.05)$.

\subsection{Mechanical Properties and Microstructure of $\mathrm{Co}-\mathrm{Cr}$ Alloy Specimens}

As shown in Table 4 , the $\mathrm{R}_{\mathrm{p} 0.2}, \mathrm{R}_{\mathrm{m}}$ and Vickers hardness of the SLM group were the highest among the three groups $(p<0.05)$, while the casting group showed the lowest values $(p<0.05)$. The SLM group also indicated a higher elongation at fracture than the milling group $(p<0.05)$. For Young's modulus, the milling group demonstrated the highest value $(p<0.05)$. All groups exceeded the minimum required of $R_{p 0.2}(80-500 \mathrm{MPa}$ ) and Young's modulus (150 GPa) for all types in ISO 22674: 2016 (type 0 , small veneered one-surface inlays, veneered crowns; type 1, veneered or un-veneered one-surface inlays, veneered crowns; type 2, crowns or inlays without restriction on the number of surfaces; type 3, multiple unit fixed prostheses; type 4, removable partial dentures, clasps, thin veneered single crowns, and full arch fixed dental prostheses; type 5, thin removable partial dentures, parts with thin cross-sections, clasps) [24]. For the elongation at fracture, the value of casting and SLM specimens were higher than the ISO requirement for type 2-5 (2-10\%), but for milling, the elongation value only beyond type $3-5(2-5 \%)$.

Table 4. Mechanical properties (means \pm standard deviations) of the casting, milling, and SLM groups.

\begin{tabular}{cccccc}
\hline Group & $\left.\mathbf{R}_{\mathbf{p} 0.2} \mathbf{( M P a}\right)$ & $\mathbf{R}_{\mathbf{m}} \mathbf{( M P a )}$ & Elongation (\%) & Young's Modulus (GPa) $^{\text {Hordness (Hv 10) }}$ \\
\hline Casting & $581 \pm 16^{\mathrm{a}}$ & $783 \pm 32^{\mathrm{a}}$ & $12 \pm 2^{\mathrm{ab}}$ & $188 \pm 19^{\mathrm{a}}$ & $303 \pm 15^{\mathrm{a}}$ \\
Milling & $672 \pm 4^{\mathrm{b}}$ & $1069 \pm 10^{\mathrm{b}}$ & $10 \pm 1^{\mathrm{a}}$ & $253 \pm 14^{\mathrm{b}}$ & $353 \pm 6^{\mathrm{b}}$ \\
SLM & $783 \pm 15^{\mathrm{c}}$ & $1158 \pm 10^{\mathrm{c}}$ & $13 \pm 1^{\mathrm{b}}$ & $195 \pm 15^{\mathrm{a}}$ & $399 \pm 24^{\mathrm{c}}$ \\
\hline
\end{tabular}

Different lowercase letters in the same column indicate significantly different groups $(p<0.05)$.

Figure 3 shows the BSE images of the cross-section of the Co-Cr specimens. The casting group displayed a typical inhomogeneous dendritic solidification microstructure consisting of dendritic areas and interdendritic areas (Figure 3a). The grain size of casting specimen is about 20-100 $\mu \mathrm{m}$. In contrast, the milling group showed a homogenous microstructure with a grain size of five- $40 \mu \mathrm{m}$ (Figure $3 \mathrm{~b}$ ). A much finer and non-equilibrium structure could be seen in SLM groups with a grain size of 2-20 $\mu \mathrm{m}$ 
(Figure 3c). In the milling and SLM groups, some second phase particles were randomly distributed in the interior and at the boundaries of the grains, especially for the SLM samples. Besides, in the SLM group, some bright blocky precipitate was dispersed randomly at the grain boundaries.
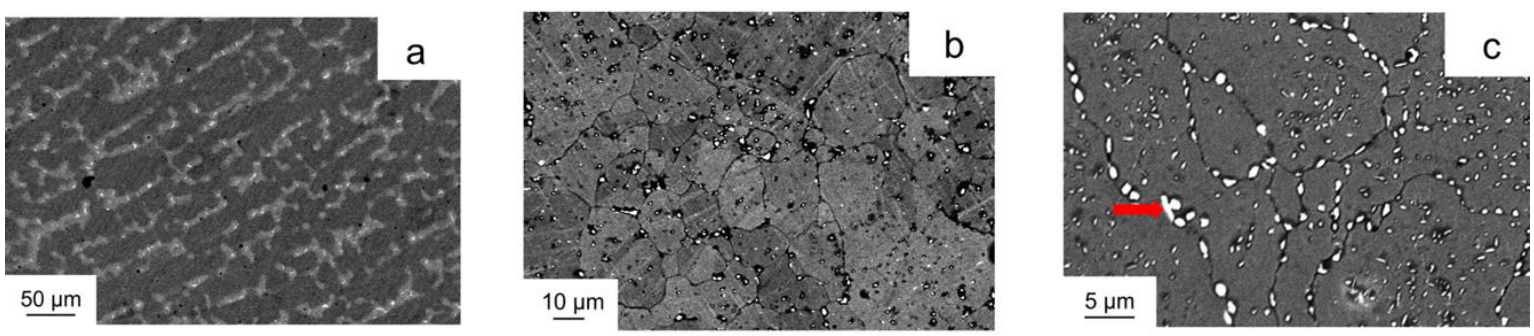

Figure 3. BSE images of Co-Cr alloy specimens: (a) casting, magnification 500 $\times$; and (b) milling, magnification 2000×; (c) SLM, magnification 5000 $\times$. The red arrow represents the bright blocky precipitate.

Figure 4 represents the fracture surfaces of the $\mathrm{Co}-\mathrm{Cr}$ specimens after the tensile test. The casting group showed a rough fracture surface with many defects (yellow arrows) (Figure 4a). Under high magnification, the surface was wavy with some cleavage planes (red arrow; Figure 4d). The milling group showed a clean and homogenous fracture surface (Figure $4 \mathrm{~b}$ ) with tear ridges and some little dimples (black and white arrows; Figure 4e). For the SLM group, the surface was also homogenous, and tear ridges were observed (Figure $4 \mathrm{c}, \mathrm{f}$ ).
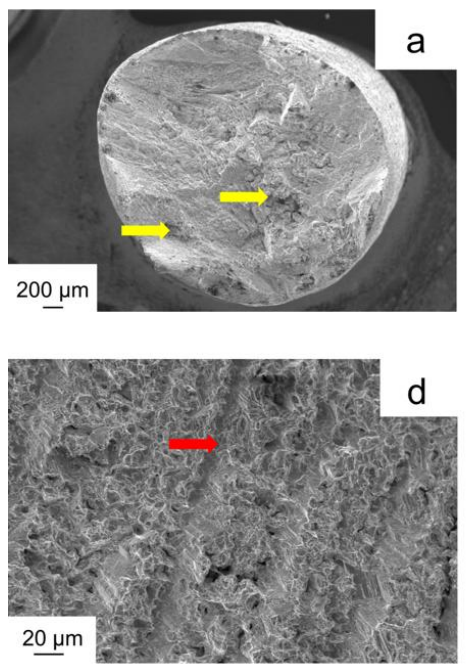
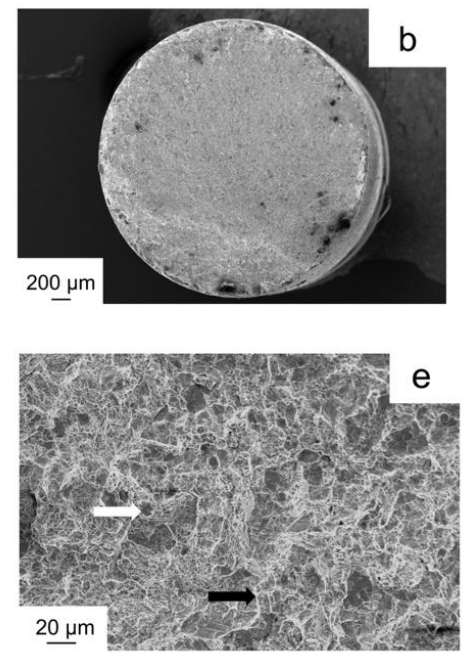
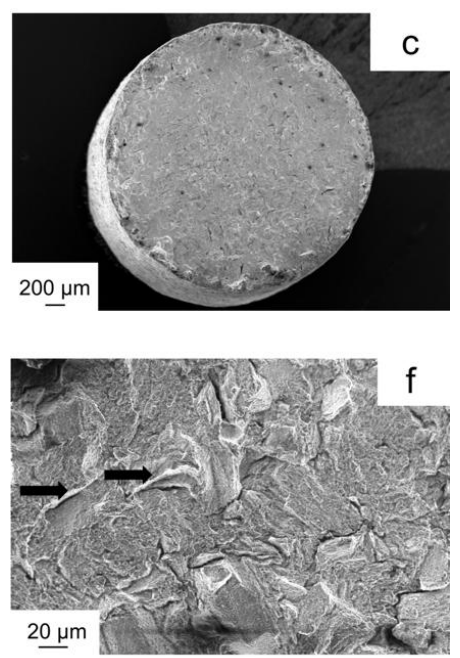

Figure 4. The fractured surfaces of the specimens after the tensile test at $65 \times$ magnification: (a) casting; (b) milling; (c) SLM and at 1000× magnification: (d) casting; (e) milling; and (f) SLM. The yellow arrows represent defects; the red arrow represents cleavage planes; the black arrows represent tear ridges, and the white arrow represents dimples.

\subsection{Bond Strength Test and Microstructure of Metal-Ceramic Specimens}

The result of the bond strength is shown in Table 5. The strength value for the casting group was lower than those for the milling and SLM groups $(p<0.05)$, while no significant differences between the milling and SLM groups were found. According to ISO 9693-1: 2012, if the bond strength for more than $66 \%$ samples $\geq 25 \mathrm{MPa}$, the group passes the test [23]. For the casting group, nine samples were lower than $25 \mathrm{MPa}$, and for the milling and SLM groups, only two samples lower than this level (the total samples in each group were 29,40 , and 40 ). So all the groups passed the bond strength due to the adequate passing rate. 
Table 5. Metal-ceramic bond strength (means \pm standard deviations) of the casting, milling, and SLM groups.

\begin{tabular}{ccc}
\hline Group & Bond Strength (MPa) & Passing Rate (\%) \\
\hline Casting & $26.86 \pm 3.48^{\mathrm{a}}$ & $69 \%$ \\
Milling & $34.22 \pm 7.77^{\mathrm{b}}$ & $95 \%$ \\
SLM & $29.88 \pm 3.62^{\mathrm{b}}$ & $95 \%$ \\
\hline
\end{tabular}

Different lowercase letters in the same column indicate significantly different groups $(p<0.05)$.

Figure 5 indicates the cross-section of the metal-ceramic specimens after the three-point bending test. For the casting group, the cracks propagated along the metal-ceramic interface smoothly without adherent ceramic (Figure 5a). While for the milling and SLM groups, cracks spread roughly with some remaining opaque ceramics (red arrows; Figure $5 b, c$ ).
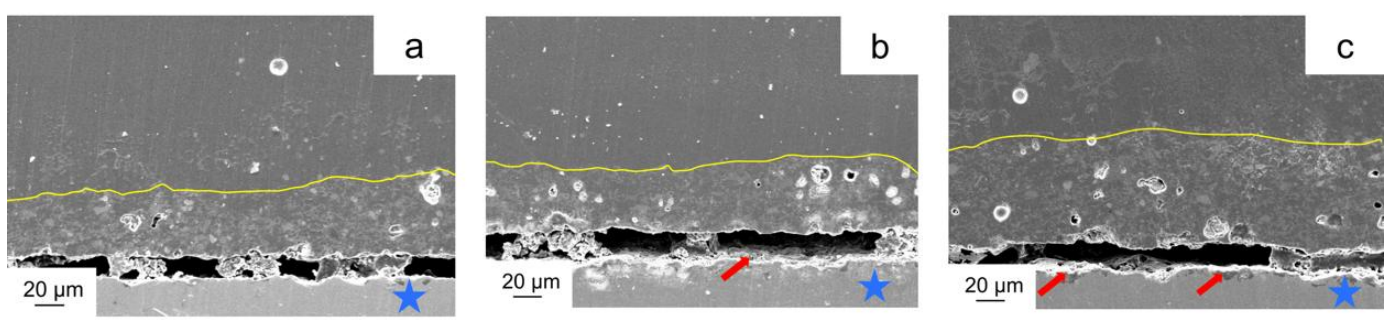

Figure 5. Representative SEM micrograph of the interface of metal-ceramic specimens after the three-point bending test (magnification 1000×): (a) casting; (b) milling; (c) SLM. The yellow lines represent the boundary of the opaque ceramic; the blue asterisks indicate the alloy substrate and the red arrows show the opaque ceramic remaining on the alloy surface.

Figure 6 shows the Co-Cr substrate surface of the specimens after debonding from the ceramic. After the three-point bending test, the cracked specimens were manually debonded to analyze the remaining ceramic area proportions on the substrate surface. The white areas represent the adherent opaque ceramic on the alloy surface (light color due to its low electrical conductivity), and the black areas indicate the $\mathrm{Co}-\mathrm{Cr}$ alloy substrate (dark color due to the high conductivity), which was confirmed by spot EDX analysis. White area (spot $\mathrm{A}$ ) contained mainly the elements $\mathrm{Si}, \mathrm{O}, \mathrm{Al}$, and $\mathrm{K}$, in contrast, the black area (spot B) consisted mainly of $\mathrm{Co}, \mathrm{Cr}$, and a metalloid element (Si). Besides, Figure 6 also indicated that after debonding, the adherent ceramic on the casting alloy surface was less than the milling and SLM groups.
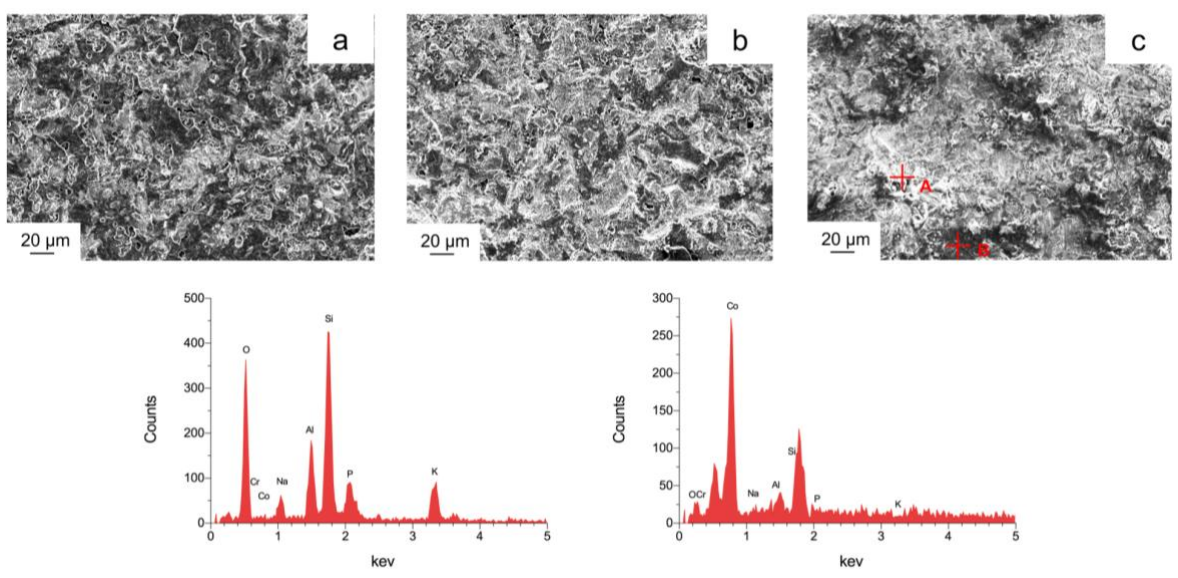

Figure 6. Representative SEM micrographs (magnification $1000 \times$ ) and EDX images of the Co-Cr alloy substrate surface after debonding from ceramic (a) SEM image, casting; (b) SEM image, milling; (c) SEM image, SLM; (d) EDX image, spot A (white area); and (e) EDX image, spot B (black area). 
Figure 7 reveals the optical microphotographs of Co-Cr alloy surface after debonding with ceramic. Compared with the casting group, the milling, and SLM groups showed a homogenous appearance without pores. Besides, more adherent ceramic on the alloy surface in milling and SLM groups was observed.
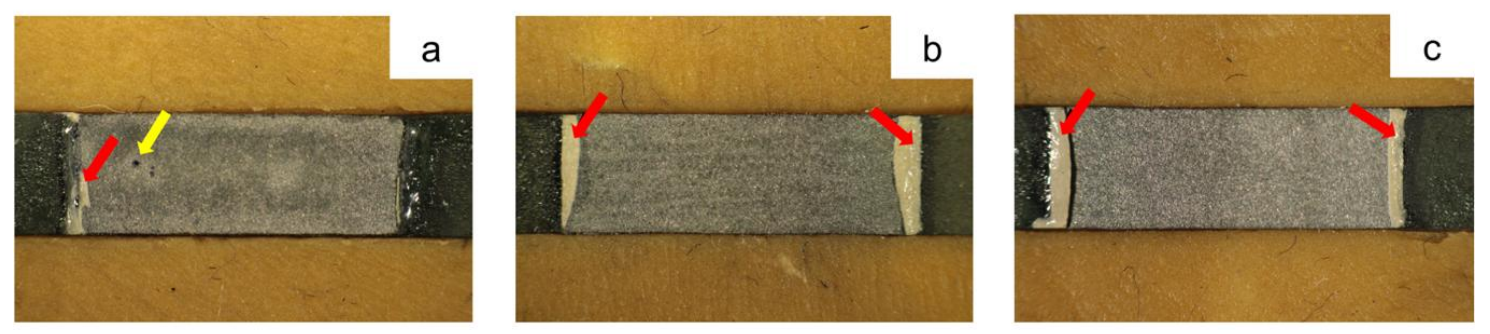

Figure 7. Optical microphotographs of $\mathrm{Co}-\mathrm{Cr}$ alloy surface after debonding with ceramic (magnification 16×) (a) casting; (b) milling; and (c) SLM. The red arrows represent adherent ceramic, and the yellow arrow represents the pores.

Table 6 shows the frequency of failure mode and the percentage of adherent ceramic area after debonding with ceramic. The failure mode in all groups was adhesive. The residual ceramic on the debonding alloy surface of the specimens was higher in the milling and SLM groups than in the casting group $(p<0.05)$.

Table 6. The failure mode analysis and the area fracture of adherence ceramic.

\begin{tabular}{ccccc}
\hline \multirow{2}{*}{ Group } & \multicolumn{2}{c}{ Frequency of the Failure Mode $(\boldsymbol{n})$} & \multirow{2}{*}{ Area Fraction of Adhering Ceramic (\%) } \\
\cline { 2 - 4 } & Adhesive & Cohesive & Mixed & \\
\hline Casting & 29 & 0 & 0 & $5.5 \pm 3.1^{\mathrm{a}}$ \\
Milling & 40 & 0 & 0 & $7.9 \pm 3.4^{\mathrm{b}}$ \\
SLM & 40 & 0 & 0 & $8.0 \pm 3.2^{\mathrm{b}}$ \\
\hline
\end{tabular}

Different lowercase letters in the same column indicate significantly different groups $(p<0.05)$.

\section{Discussion}

In this study, tested specimens of the SLM groups indicated enhanced mechanical properties and comparable metal-ceramic bond strength compared with the casting and milling groups. Therefore, the null hypothesis is rejected.

Since the evaluation of mechanical properties is complex, many standards and experimental techniques have been proposed for different purposes, which are used widely in engineering [40-43]. For dental restorations, the most commonly used standard is ISO 22674: 2016 [24]. Based on the mechanical properties result of this study (Table 4), the SLM specimens displayed better ductility, toughness, and hardness compared with the casting and milling specimens due to the higher $R_{p 0.2}, R_{m}$, and Vickers hardness values. For the resistance of fracture, the SLM group showed a higher capacity than the milling group (elongation at break). Besides, the specimens manufactured by milling had the highest rigidity among the three groups because of the higher Young's modulus values compared to the other groups. This different mechanical performance can be explained by the porosity, grain size, and second-phase particles observed in the respective groups.

Porosity is an important drawback of casting. In this study, the casting specimens exhibited an inhomogeneous appearance with many pores (Figure 7a), which is associated with the shrinkage and dendritic structure during the solidification of the casting Co-Cr alloy [44]. Differences exist in the solute distribution between the dendritic and interdendritic areas due to the dendritic segregation, and this might reduce the mechanical properties (Figure 3a) [26]. In contrast, the milling and SLM groups showed a homogenous and dense structure without pores (Figure $7 \mathrm{~b}, \mathrm{c}$ ). For the milling group, the blanks have been industrially manufactured in an optimized and controlled process, while for 
the SLM group, complete local melting and rapid solidification can minimize flaws and porosities. This might be an explanation for the superior mechanical properties of the milling and SLM specimens compared to the casting group.

Additionally, in this study, the grain size of the SLM samples was the smallest, followed by milling and casting. It is a well-known fact that smaller grains are obtained with a fast cooling process such as SLM compared to a slow cooling process like casting [34]. The milling blanks used in this study were made by the powder metallurgy method to obtain an extremely finely grained and $100 \%$ homogenous milling blank. As for the SLM powder, only the finest powder with a very narrow grain size distribution was chosen. Zhou et al. and Xin et al. also showed much finer grains and superior mechanical properties of the Co-Cr alloy fabricated by SLM compared to the casting technique $[1,26]$. In other alloys, different grain size can also lead to different mechanical performance [45]. Grain refinement can strengthen the alloy and improve the ductility and toughness, which may be an important reason for the improved mechanical performance of SLM compared to casting and milling, especially in $R_{\mathrm{p} 0.2}, R_{\mathrm{m}}$, elongation, and Vickers hardness. Besides, rapid solidification of the SLM specimens might increase the solution limit of solute elements and reduce dendritic segregation, which would also improve the mechanical performance. The rapid solidification could increase the solution strengthening effects through maintaining a high super saturation, and the supersaturated solid solution element would precipitate later and reinforce the second-phase strengthening effect [26]. This study indicated that the milling and SLM specimens contained dispersed second-phase particles (Figure 3b,c), especially in the SLM group. The second phase particles can improve the deformation resistance of the alloy because the dislocation motion is hindered by the second-phase through forming large dislocation loops, this is the so-called second-phase strengthening effect [36]. Zhou et al. and Jabbari et al. also found the presence of the second-phase microstructure in the milling and SLM specimens [26,46].

Besides, in the SLM technique, Co-Cr particles are fused by applying $\mathrm{Yb}$-fiber laser, and objects are built up layer by layer. After completion of the samples, brittle and inhomogeneous objects are obtained due to localized melting. For this reason, a post-build heat treatment process must be applied for the SLM specimens to eliminate the residual stresses, improve mechanical strength and homogeneity, but for casting and milling, this process is not necessary [5,47]. In this study, the SLM group revealed a microstructure with coarse and continuous precipitate after heat treatment (Figure 3c), which implied that furnace cooling provided sufficient time for phase precipitating [48]. Lu et al. indicated that the expected mechanical properties of SLM manufactured Co-Cr alloys could be tailored by recrystallization under the optimal heat treatment conditions, which is affected by the heating and cooling rate, holding time, cooling media, etc. [48]. Additionally, the lower mechanical properties of the casting groups could be supported by the morphology of the fracture surface. The casting group showed a defected appearance with some cleavage planes, which indicated a typical brittle fracture behavior with poor ductility (Figure 4). For the milling and SLM specimens, the fracture surfaces are dense and free of large internal defects with some tear ridges, indicating a highly ductile fracture [48].

The bond strength for the casting group was lower than those for the milling and SLM groups $(p<0.05$, Table 5), indicating an easier debonding. The different bond strength can be explained by Young's modulus, chemical bonding, mechanical interlocking, and compressive bonding.

Normally, an alloy with higher Young's modulus could be more rigid to resist bending and delamination, thus leading to stronger metal-ceramic bond strength. In this study, the casting group revealed the lowest bond strength between alloy and ceramic, which might be partially attributed to the lowest rigidity. Besides, in the calculation of bond strength (Equation (1)), correction factors, A, B, and $C$ are calculated by the Young's modulus of the tensile test. Therefore, the Young's modulus values would influence the bond strength result, even though the failure forces for each group were different.

Chemical bonding is a result of chemisorption by diffusion in the metal-ceramic interface [6], which is influenced by the oxide layer between metal and ceramic. In this study, the different bond strength among groups might relate to the different thickness of the oxide layer. Wang et al. reported a lower metal-ceramic bond strength and a thicker oxide layer between alloy and ceramic for the 
casted substrates compared with milling and SLM [36]. Akova et al. and Serra-Prat et al. also reported different manufacturing methods would lead to different oxide layer thickness [38,39]. These findings are in accordance with our assumption. The oxidation rates among different manufacturing processes should be further examined, since the oxide layer may influence the chemical bonding, and thus, the metal-ceramic bond strength.

Mechanical interlocking is another parameter for bond strength. A general consideration is that higher roughness would lead to increased metal-ceramic bond strength due to the improved contact area and mechanical interlocking on the metal-ceramic interface [49,50]. This might be an explanation for why the milled samples showed a higher bond strength compared to the casting group (Table 3). However, extensive roughness may reduce the bond between alloy and ceramic, and this might explain why the highest $R_{a}$ value of the SLM substrates did not represent the strongest bond [51]. The relatively higher roughness of the SLM group could be related to the adherence of partially melted powder particles on the alloy surface. Fox et al. studied the effect of process parameters on the surface roughness of SLM fabricated samples and revealed a large number of the partially melted powder particles on the alloy surfaces, which might affect the roughness [52]. The rougher surface of the SLM specimen surface is also related to the partial fusion of isolated powder particles during fabricating (balling phenomenon) [53]. Balling is a defect that appears when the SLM process parameters are not correctly set, and the molten tracks break into separate balls due to the surface tension effect. The SLM powder particles are loosely attached to the metal substrate on the borderline of the laser fusion, then leading to a rough surface [54]. However, the surface roughness of SLM substrates is also influenced by the manufacturing parameters, such as the powder particle size, material composition, layer thickness, geometry of the object, building direction, etc. [54]. Besides, the SLM specimens showed a better bond strength than the casting specimens, which may also be related to the gap between layers caused by the SLM manufacturing process. The gap may widen the surface area, and the bond strength may improve because of the penetration of the ceramic through the gaps. Our assumption is supported by a previous study. Wu et al. found an intermediate layer and elemental interpenetration in the metal-ceramic interface of the SLM alloy [25].

Compressive bonding at the metal-ceramic interface is also important for the metal-ceramic bond strength. Ideally, the CTE of the metal should be slightly higher than the ceramic since a compressive strength may occur in the ceramic layer during the cooling stage after firing, this is what is called a positive CTE mismatch [34]. However, the CTE values of the Co-Cr alloy and ceramic in this study were $14.1 \times 10^{-6} \mathrm{~K}^{-1}$ and 13.9-15.1 $\times 10^{-6} \mathrm{~K}^{-1}$ (Table 1), they were not expected because the value of the alloy was lower than the upper boundary value of the ceramic. The non-ideal CTE values between alloy and ceramic may be a reason for the low adherent ceramic on the alloy surface after debonding. The failure mode among all three groups was adhesive (Table 6), implying that the crack occurred between the metal and ceramic (Figures 5 and 7). Usually, adhesive failure is not an ideal situation, because this indicates a lower bond between the metal and ceramic than that within the ceramic interior and fewer destructive forces were needed to separate them [55].

Summed up, our results indicate that according to ISO 22674: 2016 and ISO 9693-1: 2012, the SLM technique is suitable to be used with the $\mathrm{Co}-\mathrm{Cr}$ alloy for fixed dental restorations comprising crowns and bridges, due to the superior mechanical properties and adequate metal-ceramic bond strength. The casted samples could also be used for crowns and bridges, but before clinical applications, the objects should be tested first due to the relatively low performance in metal-ceramic bond strength (the passing rate for the casting group in three-point bending test is $69 \%$, very close to the required rate of $66 \%$ by the ISO standard). The milling technique could only be recommended for dental bridges because the elongation at fracture did not pass the requirement for dental crowns, even though the milled samples showed a good performance in other mechanical properties and metal-ceramic bond strength. Compared with the casting and milling techniques, SLM might be a superior technique for the manufacturing of fixed dental restorations for several reasons. First, SLM can fabricate complex samples without apparent waste. Second, technician error can be reduced, and the quality 
of restorations increased because of the enhanced productivity. Third, the manufacturing costs of restoration might be decreased through large-scale production. Fourth, patients could benefit from shorter production cycles.

\section{Conclusions}

Based on the materials used and the limitations of this study, the following conclusions can be drawn:

1. The Co-Cr alloy specimens manufactured by the SLM technique have enhanced mechanical properties and comparable metal-ceramic bond strength compared with the specimens prepared by the casting and milling techniques;

2. The microstructure of the Co-Cr alloy depends on the manufacturing techniques. Compared with casting and milling, the SLM specimens have relatively homogeneously distributed fine grains and more dispersed second-phase particles;

3. According to the ISO 22674: 2016 and ISO 9693-1: 2012, the SLM technique can be used for fabricating dental bridges and crowns. SLM might be superior to the traditional manufacturing techniques for fixed dental restorations.

Author Contributions: Conceptualization, S.S.; Formal analysis, X.H.; Methodology, C.S., E.S. and S.S.; Project administration, S.S.; Writing original draft, X.H.; Writing, review \& editing, T.S., L.S., J.G.-G., F.R., and S.S.

Funding: The China Scholarship Council (CSC) is gratefully acknowledged for the financial support of Xingting Han (Grant 201606280045). We further acknowledge open access publishing funding by Deutsche Forschungsgemeinschaft (DFG) and the University of Tübingen.

Acknowledgments: The authors would like to thank M. Sc Rolf Ebert and ZTM Katharina Fuchs-Ebert for the SLM and casting groups and veneering ceramic. $\mathrm{Co}-\mathrm{Cr}$ alloy specimen preparation by Dentaurum, Ispringen, Germany is acknowledged.

Conflicts of Interest: The authors declare no conflict of interest.

\section{Abbreviations}

$\begin{array}{ll}\text { ANOVA } & \text { One-way analysis of variance } \\ \text { BSE } & \text { Backscattered electrons } \\ \text { CAD-CAM } & \text { Computer-aided design and computer-aided manufacturing } \\ \text { Co-Cr } & \text { Cobalt-chromium } \\ \text { CTE } & \text { Coefficient of thermal expansion } \\ \text { EDX } & \text { Energy dispersive X-Ray spectroscopy } \\ \text { PFM } & \text { Porcelain-fused-to-metal } \\ \mathrm{R}_{\mathrm{a}} & \text { Arithmetic average of the roughness profile } \\ \mathrm{R}_{\mathrm{m}} & \text { Ultimate tensile strength } \\ \mathrm{R}_{\mathrm{p} 0.2} & 0.2 \% \text { yield strength } \\ \text { SEM } & \text { Scanning electron microscopy } \\ \text { SLM } & \text { Selective laser melting }\end{array}$

\section{References}

1. Xin, X.Z.; Chen, J.; Xiang, N.; Gong, Y.; Wei, B. Surface characteristics and corrosion properties of selective laser melted Co-Cr dental alloy after porcelain firing. Dent. Mater. 2014, 30, 263-270. [CrossRef] [PubMed]

2. Migliario, M.; Mergoni, G.; Vescovi, P.; De Martino, I.; Alessio, M.; Benzi, L.; Renò, F.; Fusco, V. Osteonecrosis of the jaw (ONJ) in osteoporosis patients: Report of delayed diagnosis of a multisite case and commentary about risks coming from a restricted ONJ definition. Dent. J. 2017, 5, 13. [CrossRef] [PubMed]

3. Roberts, H.W.; Berzins, D.W.; Moore, B.K.; Charlton, D.G. Metal-ceramic alloys in dentistry: A review. J. Prosthodont. 2009, 18, 188-194. [CrossRef] [PubMed]

4. Kim, D.Y.; Kim, J.H.; Kim, H.Y.; Kim, W.C. Comparison and evaluation of marginal and internal gaps in cobalt-chromium alloy copings fabricated using subtractive and additive manufacturing. J. Prosthodont. Res. 2018, 62, 56-64. [CrossRef] [PubMed] 
5. Antanasova, M.; Kocjan, A.; Kovač, J.; Žužek, B.; Jevnikar, P. Influence of thermo-mechanical cycling on porcelain bonding to cobalt-chromium and titanium dental alloys fabricated by casting, milling, and selective laser melting. J. Prosthodont. Res. 2017, 62, 184-194. [CrossRef] [PubMed]

6. Li, J.; Chen, C.; Liao, J.; Liu, L.; Ye, X.; Lin, S.; Ye, J. Bond strengths of porcelain to cobalt-chromium alloys made by casting, milling, and selective laser melting. J. Prosthet. Dent. 2017, 118, 69-75. [CrossRef] [PubMed]

7. Sánchez Egea, A.J.; Martynenko, V.; Martínez Krahmer, D.; López de Lacalle, L.N.; Benítez, A.; Genovese, G. On the cutting performance of segmented diamond blades when dry-cutting concrete. Materials 2018, 11, 264. [CrossRef] [PubMed]

8. Strub, J.R.; Rekow, E.D.; Witkowski, S. Computer-aided design and fabrication of dental restorations. J. Am. Dent. Assoc. 2006, 137, 1289-1296. [CrossRef] [PubMed]

9. Demir, A.G.; Previtali, B. Additive manufacturing of cardiovascular CoCr stents by selective laser melting. Mater. Des. 2017, 119, 338-350. [CrossRef]

10. Lu, Y.; Ren, L.; Wu, S.; Yang, C.; Lin, W.; Xiao, S.; Yang, Y.; Yang, K.; Lin, J. CoCrWCu alloy with antibacterial activity fabricated by selective laser melting: Densification, mechanical properties and microstructural analysis. Powder Technol. 2018, 325, 289-300. [CrossRef]

11. Lu, Y.; Ren, L.; Xu, X.; Yang, Y.; Wu, S.; Luo, J.; Yang, M.; Liu, L.; Zhuang, D.; Yang, K. Effect of Cu on microstructure, mechanical properties, corrosion resistance and cytotoxicity of CoCrW alloy fabricated by selective laser melting. J. Mech. Behav. Biomed. Mater. 2018, 81, 130-141. [CrossRef] [PubMed]

12. Hedberg, Y.S.; Qian, B.; Shen, Z.; Virtanen, S.; Odnevall Wallinder, I. In vitro biocompatibility of CoCrMo dental alloys fabricated by selective laser melting. Dent. Mater. 2014, 30, 525-534. [CrossRef] [PubMed]

13. Lu, Y.; Zhao, C.; Ren, L.; Guo, S.; Gan, Y.; Yang, C.; Wu, S.; Lin, J.; Huang, T.; Yang, K. Preliminary assessment of metal-porcelain bonding strength of CoCrW alloy after 3 wt. \% Cu addition. Mater. Sci. Eng. C 2016, 63, 37-45. [CrossRef] [PubMed]

14. Martínez, S.; Lamikiz, A.; Ukar, E.; Calleja, A.; Arrizubieta, J.A.; de Lacalle, L.N.L. Analysis of the regimes in the scanner-based laser hardening process. Opt. Lasers Eng. 2017, 90, 72-80. [CrossRef]

15. Badrossamay, M.; Childs, T.H.C. Further studies in selective laser melting of stainless and tool steel powders. Int. J. Mach. Tools Manuf. 2007, 47, 779-784. [CrossRef]

16. Thijs, L.; Verhaeghe, F.; Craeghs, T.; Van Humbeeck, J.; Kruth, J.-P. A study of the microstructural evolution during selective laser melting of Ti-6Al-4V. Acta Mater. 2010, 58, 3303-3312. [CrossRef]

17. Byeong-Don, J.O.O.; Jeong-Hwan, J.; Jae-Ho, L.E.E.; Young-Myung, S.O.N.; Young-Hoon, M. Selective laser melting of Fe-Ni-Cr layer on AISI H13 tool steel. Trans. Nonferrous Met. Soc. China 2009, 19, 921-924.

18. Wysocki, B.; Idaszek, J.; Zdunek, J.; Rożniatowski, K.; Pisarek, M.; Yamamoto, A.; Święszkowski, W. The influence of selective laser melting (SLM) process parameters on in-vitro cell response. Int. J. Mol. Sci. 2018, 19, 1619. [CrossRef] [PubMed]

19. Yadroitsev, I.; Bertrand, P.; Smurov, I. Parametric analysis of the selective laser melting process. Appl. Surf. Sci. 2007, 253, 8064-8069. [CrossRef]

20. Kim, B.; Zhang, Y.; Pines, M.; Thompson, V.P. Fracture of porcelain-veneered structures in fatigue. J. Dent. Res. 2007, 86, 142-146. [CrossRef] [PubMed]

21. Xin, X.; Xiang, N.; Chen, J.; Xu, D.; Wei, B. Corrosion characteristics of a selective laser melted Co-Cr dental alloy under physiological conditions. J. Mater. Sci. 2012, 47, 4813-4820. [CrossRef]

22. Zeng, L.; Xiang, N.; Wei, B. A comparison of corrosion resistance of cobalt-chromium-molybdenum metal ceramic alloy fabricated with selective laser melting and traditional processing. J. Prosthet. Dent. 2014, 112, 1217-1224. [CrossRef] [PubMed]

23. ISO 9693-1:2012 Dentistry—Compatibility Testing—Part 1: Metal-Ceramic Systems; International Organization for Standardization: Geneva, Switzerland, 2012.

24. ISO 22674:2016 Dentistry—Metallic Materials for Fixed and Removable Restorations and Appliances; International Organization for Standardization: Geneva, Switzerland, 2016.

25. Wu, L.; Zhu, H.; Gai, X.; Wang, Y. Evaluation of the mechanical properties and porcelain bond strength of cobalt-chromium dental alloy fabricated by selective laser melting. J. Prosthet. Dent. 2014, 111, 51-55. [CrossRef] [PubMed]

26. Zhou, Y.; Li, N.; Yan, J.; Zeng, Q. Comparative analysis of the microstructures and mechanical properties of Co-Cr dental alloys fabricated by different methods. J. Prosthet. Dent. 2018. [CrossRef] [PubMed]

27. Fischer, J. Ceramic bonding to a dental gold-titanium alloy. Biomaterials 2002, 23, 1303-1311. [CrossRef] 
28. Johnson, T.; van Noort, R.; Stokes, C.W. Surface analysis of porcelain fused to metal systems. Dent. Mater. 2006, 22, 330-337. [CrossRef] [PubMed]

29. Li, K.C.; Tran, L.Y.; Prior, D.J.; Waddell, J.N.; Swain, M.V. Porcelain bonding to novel Co-Cr alloys: Influence of interfacial reactions on phase stability, plasticity and adhesion. Dent. Mater. 2016, 32, 1504-1512. [CrossRef] [PubMed]

30. De Melo, R.M.; Travassos, A.C.; Neisser, M.P. Shear bond strengths of a ceramic system to alternative metal alloys. J. Prosthet. Dent. 2005, 93, 64-69. [CrossRef] [PubMed]

31. Huang, H.; Lin, M.; Lee, T.; Yang, H.; Chen, F.; Wu, S.; Hsu, C. Effect of chemical composition of Ni-Cr dental casting alloys on the bonding characterization between porcelain and metal. J. Oral Rehabil. 2005, 32, $206-212$. [CrossRef] [PubMed]

32. Nikellis, I.; Levi, A.; Zinelis, S. Effect of soldering on the metal-ceramic bond strength of an Ni-Cr base alloy. J. Prosthet. Dent. 2005, 94, 435-439. [CrossRef] [PubMed]

33. Saji, V.S.; Choe, H.-C. Electrochemical behavior of $\mathrm{Co}-\mathrm{Cr}$ and Ni-Cr dental cast alloys. Trans. Nonferrous Met. Soc. China 2009, 19, 785-790. [CrossRef]

34. Prashanth, K.G.; Scudino, S.; Klauss, H.J.; Surreddi, K.B.; Löber, L.; Wang, Z.; Chaubey, A.K.; Kühn, U.; Eckert, J. Microstructure and mechanical properties of Al-12Si produced by selective laser melting: Effect of heat treatment. Mater. Sci. Eng. A 2014, 590, 153-160. [CrossRef]

35. Kim, H.R.; Jang, S.H.; Kim, Y.K.; Son, J.S.; Min, B.K.; Kim, K.H.; Kwon, T.Y. Microstructures and mechanical properties of Co-Cr dental alloys fabricated by three CAD/CAM-based processing techniques. Materials 2016, 9. [CrossRef] [PubMed]

36. Wang, H.; Feng, Q.; Li, N.; Xu, S. Evaluation of metal-ceramic bond characteristics of three dental Co-Cr alloys prepared with different fabrication techniques. J. Prosthet. Dent. 2016, 116, 916-923. [CrossRef] [PubMed]

37. Örtorp, A.; Jönsson, D.; Mouhsen, A.; Vult Von Steyern, P. The fit of cobalt-chromium three-unit fixed dental prostheses fabricated with four different techniques: A comparative in vitro study. Dent. Mater. 2011, 27, 356-363. [CrossRef] [PubMed]

38. Serra-Prat, J.; Cano-Batalla, J.; Cabratosa-Termes, J.; Figueras-Àlvarez, O. Adhesion of dental porcelain to cast, milled, and laser-sintered cobalt-chromium alloys: Shear bond strength and sensitivity to thermocycling. J. Prosthet. Dent. 2014, 112, 600-605. [CrossRef] [PubMed]

39. Akova, T.; Ucar, Y.; Tukay, A.; Balkaya, M.C.; Brantley, W.A. Comparison of the bond strength of laser-sintered and cast base metal dental alloys to porcelain. Dent. Mater. 2008, 24, 1400-1404. [CrossRef] [PubMed]

40. Tabernero, I.; Lamikiz, A.; Martinez, S.; Ukar, E.; De Lacalle, L.N.L. Modelling of energy attenuation due to powder flow-laser beam interaction during laser cladding process. J. Mater. Process. Technol. 2012, 212, 516-522. [CrossRef]

41. Dixit, U.S.; Joshi, S.N.; Davim, J.P. Incorporation of material behavior in modeling of metal forming and machining processes: A review. Mater. Des. 2011, 32, 3655-3670. [CrossRef]

42. Silva, C.M.A.; Rosa, P.A.R.; Martins, P.A.F. Innovative testing machines and methodologies for the mechanical characterization of materials. Exp. Tech. 2016, 40, 569-581. [CrossRef]

43. Krahmer, D.M.; Polvorosa, R.; de Lacalle, L.N.; Alonso-Pinillos, U.; Abate, G.; Riu, F. Alternatives for specimen manufacturing in tensile testing of steel plates. Exp. Tech. 2016, 40, 1555-1565. [CrossRef]

44. Koutsoukis, T.; Zinelis, S.; Eliades, G.; Al-Wazzan, K.; Al Rifaiy, M.; Al Jabbari, Y.S. Selective laser melting technique of Co-Cr dental alloys: A review of structure and properties and comparative analysis with other available techniques. J. Prosthodont. 2015, 24, 303-312. [CrossRef] [PubMed]

45. Beranoagirre, A.; Olvera, D.; de Lacalle, L.N. Milling of gamma titanium-Aluminum alloys. Int. J. Adv. Manuf. Technol. 2012, 62, 83-88. [CrossRef]

46. Al Jabbari, Y.S.; Koutsoukis, T.; Barmpagadaki, X.; Zinelis, S. Metallurgical and interfacial characterization of PFM Co-Cr dental alloys fabricated via casting, milling or selective laser melting. Dent. Mater. 2014, 30, e79-e88. [CrossRef] [PubMed]

47. Ayyıldız, S.; Soylu, E.H.; Ide, S.; Kılıç, S.; Sipahi, C.; Pişkin, B.; Gökçe, H.S. Annealing of Co-Cr dental alloy: Effects on nanostructure and Rockwell hardness. J. Adv. Prosthodont. 2013, 5, 471-478. [CrossRef] [PubMed]

48. Lu, Y.; Wu, S.; Gan, Y.; Zhang, S.; Guo, S.; Lin, J.; Lin, J. Microstructure, mechanical property and metal release of As-SLM CoCrW alloy under different solution treatment conditions. J. Mech. Behav. Biomed. Mater. 2015, 55, 179-190. [CrossRef] [PubMed] 
49. Reyes, M.J.D.; Oshida, Y.; Andres, C.J.; Barco, T.; Hovijitra, S.; Brown, D. Titanium-porcelain system. Part III: Effects of surface modification on bond strengths. Biomed. Mater. Eng. 2001, 11, 117-136. [PubMed]

50. Maressa, P.; Anodio, L.; Bernasconi, A.; Demir, A.G.; Previtali, B. Effect of surface texture on the adhesion performance of laser treated Ti6Al4V alloy. J. Adhes. 2015, 91, 518-537. [CrossRef]

51. Henriques, B.; Faria, S.; Soares, D.; Silva, F.S. Hot pressing effect on the shear bond strength of dental porcelain to CoCrMoSi alloy substrates with different surface treatments. Mater. Sci. Eng. C 2013, 33, 557-563. [CrossRef] [PubMed]

52. Fox, J.C.; Moylan, S.P.; Lane, B.M. Effect of process parameters on the surface roughness of overhanging structures in laser powder bed fusion additive manufacturing. Procedia CIRP 2016, 45, 131-134. [CrossRef]

53. Bae, E.-J.; Kim, J.-H.; Kim, W.-C.; Kim, H.-Y. Bond and fracture strength of metal-ceramic restorations formed by selective laser sintering. J. Adv. Prosthodont. 2014, 6, 266. [CrossRef] [PubMed]

54. Vaithilingam, J.; Prina, E.; Goodridge, R.D.; Hague, R.J.M.; Edmondson, S.; Rose, F.R.A.J.; Christie, S.D.R. Surface chemistry of Ti6Al4V components fabricated using selective laser melting for biomedical applications. Mater. Sci. Eng. C 2016, 67, 294-303. [CrossRef] [PubMed]

55. Xiang, N.; Xin, X.Z.; Chen, J.; Wei, B. Metal-ceramic bond strength of Co-Cr alloy fabricated by selective laser melting. J. Dent. 2012, 40, 453-457. [CrossRef] [PubMed]

(c) 2018 by the authors. Licensee MDPI, Basel, Switzerland. This article is an open access article distributed under the terms and conditions of the Creative Commons Attribution (CC BY) license (http:/ / creativecommons.org/licenses/by/4.0/). 